Journal of Polymer Science and Engineering (2018) Volume 1 doi:10.24294/jpse.v1i4.413

\title{
Preparation of defect free TFC FO membranes using robust and highly porous ceramic substrate
}

\author{
Jincai Su, Yanyan Wei, Hui Li
}

School of Life Sciences \& Chemical Technology, Ngee Ann Polytechnic, 535 Clementi Road, Singapore

\begin{abstract}
In this study, robust and defect-free thin film composite (TFC) forward osmosis (FO) membranes have been successfully fabricated using ceramic hollow fibers as the substrate. Polydopamine (PDA) coating under controlled conditions is effective to reduce the surface pores of the substrate and make the substrate smooth enough for the interfacial polymerization. The pure water permeability (A), solute permeability (B) and structural parameter (S) of the resultant FO membrane are $0.854 \mathrm{~L} \cdot \mathrm{m}^{-2} \mathrm{~h}^{-1} \mathrm{bar}^{-1}(\mathrm{LMH} / \mathrm{Bar}) 0.186 \mathrm{~L} \cdot \mathrm{m}^{-2} \mathrm{~h}^{-1}(\mathrm{LMH})$ and $1720 \mu \mathrm{m}$, respectively. The water flux and reverse draw solute flux are measured using $\mathrm{NaCl}$ and proprietary ferric sodium citrate (FeNaCA) draw solutions at low and high osmotic pressure ranges. With increasing the osmotic pressure, higher water flux is obtained but its increase is not directly proportional to the increase in the osmotic pressure. At the membrane surface, the effect of dilutive concentration polarization is much less serious for FeNaCA draw solutions. At an osmotic pressure of 89.6 bar, the developed TFC membrane generates water fluxes of 11.5 and $30.0 \mathrm{LMH}$ using $\mathrm{NaCl}$ and synthesized FeNaCA draw solutions. The corresponding reverse draw solute flux is $7.0 \mathrm{~g} \cdot \mathrm{m}^{-2} \mathrm{~h}^{-1}(\mathrm{gMH})$ for NaCl draw solution but it is not detectable for FeNaCA draw solution. This means that the developed TFC FO membranes are defect free and their surface pores are at molecular level. The performance of the developed TFC FO membranes are also demonstrated for the enrichment of BSA protein.
\end{abstract}

Keywords: Defect-free; Thin film composite; Forward osmosis; Reverse draw solute flux; Protein enrichment

\section{Introduction}

Forward Osmosis (FO) is a process where there is net movement of water across a selectively permeable membrane from the feed solution to draw solution. The natural driving force is resulted from the osmotic pressure difference between the two solutions ${ }^{[1,2]}$. Compared with conventional pressure driven membrane processes such as reverse osmosis (RO), FO has the merits of high water recovery rate, minimized brine discharge, low fouling propensity, and low energy requirements ${ }^{[3-5]}$. Thus, FO has been considered as a promising membrane technology for various disciplines, such as wastewater reclamation ${ }^{[6]}$, seawater desalination $^{[7]}$, protein or pharmaceutical enrichment ${ }^{[8,9]}$, and food processing ${ }^{[10]}$.

In the last decade, many efforts have been put on FO research and remarkable progress has been made on the two essential components of FO, one being the semipermeable membrane which has excellent water permeability and rejection to any solutes and the other being the reagent named as draw solution which has high osmotic pressure ${ }^{[1,12]}$. FO membranes with various configurations such as flat sheet, hollow fiber, and thin film composite (TFC) have been developed from cellulose acetate (CA), cellulose triacetate (CTA), polybenzimidazole (PBI), polyamide, and polyamide-imide (PAI) etc. ${ }^{[13-19]}$. However, only cellulose triacetate (CTA), and polyamide thin film composite (TFC) membranes are available in commercial scale. The most important properties of FO membranes are the water permeability coefficient, solute permeability coefficient, hydrophilicity, and the sublayer structure. In terms of water permeability and solute permeability, polyamide TFC membranes are generally better than CTA membranes.

Polyamide TFC FO membranes are exclusively prepared via an interfacial polymerization process. To achieve desired water flux, previous research works have 
mainly focused on the optimization of the separating layer $^{[12]}$, and modification of the support matrix by incorporating functional materials such as nanotube ${ }^{[20]}$. Despite the significant improvements, one big challenge that hinders their universal applications is the flat sheet configuration, which cannot offer high packing density $^{[21]}$. Single- and dual-layer hollow fiber membranes have been also developed and displayed promising FO performance ${ }^{[15,22]}$. However, the limitation of these self-supported hollow fiber membranes is the small internal diameter, which is normally below $1 \mathrm{~mm}$. As such, laminar flow is normally applied in the lumen side (either flowing the feed or draw solution) in order to mitigate the pressure buildup. In consequence, the influence of boundary layer on the FO performance is significant and the operation conditions are not suitable for large scale processes. Furthermore, the substrate of TFC FO membranes is mainly polymer based and it is made highly porous to reduce the resistance for water transport. The substrate is thus mechanically weak and could not guarantee the integrity of the selective layer as it easily collapses. To form thin polyamide separating layer on strong tubular inorganic substrate through interfacial polymerization might be the potential solution to concurrently achieve high packing density, excellent mechanical robustness, and desired turbulent flow ${ }^{[23]}$. In this study, we have developed robust and defect-free TFC FO membranes by forming polyamide thin layer on the inner surface of ceramic hollow fibers. The as-developed membranes are characterized in terms of morphology, water permeability, solute permeability, and structural parameter. The FO performance of the ceramic TFC membranes is evaluated using $\mathrm{NaCl}$ and proprietary ferric sodium citrate (FeNaCA) draw solutions. Using Bovine Serum Albumin (BSA) as the model material, we have demonstrated the applicability of using the ceramic TFC membranes for liquid product enrichment via FO processes.

\section{Experimental}

\subsection{Materials}

Ceramic hollow fiber membranes (length $460 \mathrm{~mm}$, outer diameter $4 \mathrm{~mm}$, inner diameter of $3 \mathrm{~mm}$, and average pore diameter $20 \mathrm{~nm}$ ) purchased from Hyflux Membrane Manufacturing (S) Pte Ltd were used as the substrate for the fabrication of TFC FO membranes. Dopamine, hexene ( $>99.5 \%$ ), ethanol (HPLC grade) and sodium chloride $(\mathrm{NaCl}, \geq 99 \%)$ were purchased from Merck. M-phenylenediamine (MPD, > 99\%) and trimesoylchloride (TMC, > 98\%), and BSA were supplied by Sigma-Aldrich. All the chemicals were used as received without further purification. Deionized (DI) water with conductivity $<1.0 \mu \mathrm{S} / \mathrm{cm}$ was obtained from a Heal Force Water Purification System (NW20VF, Heal Force). Proprietary draw solute, ferric sodium citrate coded as FeNaCA, was synthesized in our lab using a method similar to that reported by Ge and coworkers ${ }^{[24]}$.

\subsection{Fabrication of TFC membrane}

Ceramic hollow fiber membranes with a length of $\sim 230 \mathrm{~mm}$ were firstly cleaned with ethanol for $30 \mathrm{~min}$ and flushed thoroughly with DI water. Subsequently, an intermediate layer was formed at the inner surface of the ceramic hollow fiber membranes by way of PDA coating. To coat PDA, the ceramic hollow fibers were immersed in $2 \mathrm{~g} \cdot \mathrm{L}^{-1}$ dopamine solution with the outer surface wrapped with Teflon tape. After the coating, the excess solution was removed with air blowing and the coated substrate was dried at $100^{\circ} \mathrm{C}$ under vacuum.

The PDA-coated ceramic hollow fiber membranes were used as the substrate for the fabrication of TFC membranes at the inner surface. Specifically, the coated hollow fiber membranes were firstly immersed in $2 \mathrm{wt} \%$ MPD aqueous solution for $10 \mathrm{~min}$. After the excess MPD solution was removed through air blowing, the hollow fibers were then immersed in $0.1 \mathrm{wt} \% \mathrm{TMC}$ solution for $2 \mathrm{~min}$ to form the polyamide selective layer. The resultant ceramic TFC hollow fiber membranes were soaked in $50 \mathrm{wt} \%$ glycerol aqueous solution for $48 \mathrm{~h}$ and then air-dried at room temperature before the characterization and membrane module fabrication.

\subsection{Study of membrane morphology}

The morphology of the pristine ceramic hollow fiber membranes and the membranes after cleaning, PDA coating and interfacial polymerization was inspected using a Field Emission Scanning Electron Microscope (FESEM, JEOL JSM-7600F, Japan). For FESEM inspection, the membrane samples were fractured and coated with platinum using a sputtering coater (JEOL JFC-1600, Japan).

\subsection{Membrane characterization through FO}




\section{experiments}

After thoroughly dried at room temperature, one piece of ceramic hollow fiber TFC membrane was mounted into a $\Phi 3 / 8$ inch stainless steel tubing and two ends were sealed with epoxy resin to assemble the membrane module. The membrane modules were subjected to $\mathrm{FO}$ tests using 4 dilute $\mathrm{NaCl}$ draw solutions with the active layer facing the feed (AL-FS mode). During the FO tests, the concentration of the draw solution was changed in each stage of the experiment following the method reported by Tiraferri and co-workers ${ }^{[25]}$.

The water flux, $\mathrm{J}_{\mathrm{w}}\left(\mathrm{L} \cdot \mathrm{m}^{-2} \mathrm{~h}^{-1}\right.$ or $\left.\mathrm{LMH}\right)$, was calculated from the volume change of the feed solution using equation:

$$
\mathrm{J}_{\mathrm{w}}=\frac{\Delta \mathrm{V}}{\mathrm{A}_{\mathrm{m}} \Delta \mathrm{t}}
$$

where $\Delta \mathrm{V}(\mathrm{L})$ is the volume change of the feed solution over a FO testing time $\Delta t(h)$, and $A_{m}$ is the effective membrane surface area $\left(\mathrm{m}^{2}\right)$. The reverse flux of draw solutes, $\mathrm{J}_{\mathrm{s}}\left(\mathrm{g} \cdot \mathrm{m}^{-2} \mathrm{~h}^{-1}\right.$ or $\left.\mathrm{gMH}\right)$, in FO refers to the amount of draw solutes reversely permeating from the draw solution to the feed. Since the draw solutions are conductive and the concentration of draw solutes is proportional to their electrical conductivity in dilute solutions, the amount of draw solutes permeating to the feed solution was determined by measuring the variation of its conductivity using a calibrated conductivity meter (Thermo Scientific Orion Star A215, USA). The value of $\mathrm{J}_{\mathrm{S}}$ was determined from the increase in the conductivity of the feed:

$$
\mathrm{J}_{\mathrm{s}}=\frac{\left(\mathrm{C}_{\mathrm{t}} \mathrm{V}_{\mathrm{t}}\right)-\left(\mathrm{C}_{0} \mathrm{~V}_{0}\right)}{\Delta \mathrm{A} \mathrm{A}_{\mathrm{m}}}
$$

where $\mathrm{C}_{0}\left(\mathrm{~mol}^{\cdot} \mathrm{L}^{-1}\right)$ and $\mathrm{V}_{0}(\mathrm{~L})$ are the initial draw solute concentration and the initial volume of the feed while $C_{t}$ $\left(\mathrm{mol}^{\cdot} \cdot \mathrm{L}^{-1}\right)$ and $\mathrm{V}_{\mathrm{t}}(\mathrm{L})$ are the draw solute concentration and the volume of the feed solution over a FO testing time $\Delta \mathrm{t}$, respectively.

The measured water flux and reverse draw solute flux could be correlated through the following equations ${ }^{[25]}$ :

$$
\begin{aligned}
& J_{W}=A\left\{\frac{\pi_{D} \exp \left(-\frac{J_{W} S}{D}\right)-\pi_{F} \exp \left(\frac{J_{W}}{k}\right)}{1+\frac{B}{J_{W}}\left[\exp \left(\frac{(W)}{k}\right)-\exp \left(-\frac{J_{W} S}{D}\right)\right]}\right\} \\
& J_{S}=B\left\{\frac{c_{D} \exp \left(-\frac{J_{W} S}{D}\right)-c_{F} \exp \left(\frac{d w}{k}\right)}{1+\frac{B}{J_{W}}\left[\exp \left(\frac{J_{w}}{k}\right)-\exp \left(-\frac{J_{W} S}{D}\right)\right]}\right\}
\end{aligned}
$$

where A, B and S are the water permeability coefficient, the solute permeability coefficient and the structural parameter of the FO membrane, $C_{D}$ and $\pi_{D}$ are the bulk concentration and osmotic pressure of the draw solution, $\mathrm{C}_{\mathrm{F}}$ and $\pi_{\mathrm{F}}$ are the bulk concentration and osmotic pressure of the feed solution, $\mathrm{k}$ is the mass transfer coefficient and D is the bulk solute diffusion coefficient. For each draw solution concentration, the water flux and reverse draw solute flux are named as $\mathrm{J}_{\mathrm{w}, \mathrm{i}}$ and $\mathrm{J}_{\mathrm{s}, \mathrm{i}}$, where $\mathrm{i}=1,2,3,4$. The membrane parameters, $\mathrm{A}, \mathrm{B}$ and $\mathrm{S}$, were calculated from the four experimental water and draw solute fluxes using Tiraferri's excel spreadsheet.

\subsection{Performance evaluation through FO tests}

The FO performance of the ceramic TFC hollow fiber membranes was examined by using a lab-scale FO set-up and the detailed testing procedure was described elsewhere ${ }^{[13]}$. Aqueous solutions of two types of draw solute, i.e., $\mathrm{NaCl}$ and proprietary $\mathrm{FeNaCA}$, were used as draw solutions. The volumetric flow rates on the lumen and shell sides were fixed at $0.3 \mathrm{~L} \cdot \mathrm{min}^{-1}$. For comparison, DI water was firstly used as the feed solution and operated with the membrane active layer facing the draw solution (i.e., AL-DS mode). To minimize the effect of the draw solution dilution on the performance, the duration of the $\mathrm{FO}$ tests was fixed at $15 \mathrm{~min}$.

The FO performance of the ceramic TFC hollow fiber membranes was also evaluated for the enrichment of BSA protein. In the enrichment experiment, $400 \mathrm{~mL}$ BSA solution (200 ppm) was used as the feed and the FO system was operated at the AL-DS mode. To examine the possible reverse leakage of the draw solutes and the influence on protein, the feed solution before and after FO test was subjected to the Circular Dichroism (CD) spectra measurement using a Jasco Spectropolarimeter (Model J-800, Japan).

\section{Results and discussion \\ 3.1 Membrane morphology}

As shown in Figure 1, the pristine ceramic hollow fiber membranes have asymmetric structure with the inner surface smoother and denser than the outer surface. The inner surface is chosen as the surface for the PDA coating and the formation of polyamide selective layer. The average pore size of the ceramic membranes is around $20 \mathrm{~nm}$ and some voids or defects with relatively large dimension can be seen on the inner surface. 


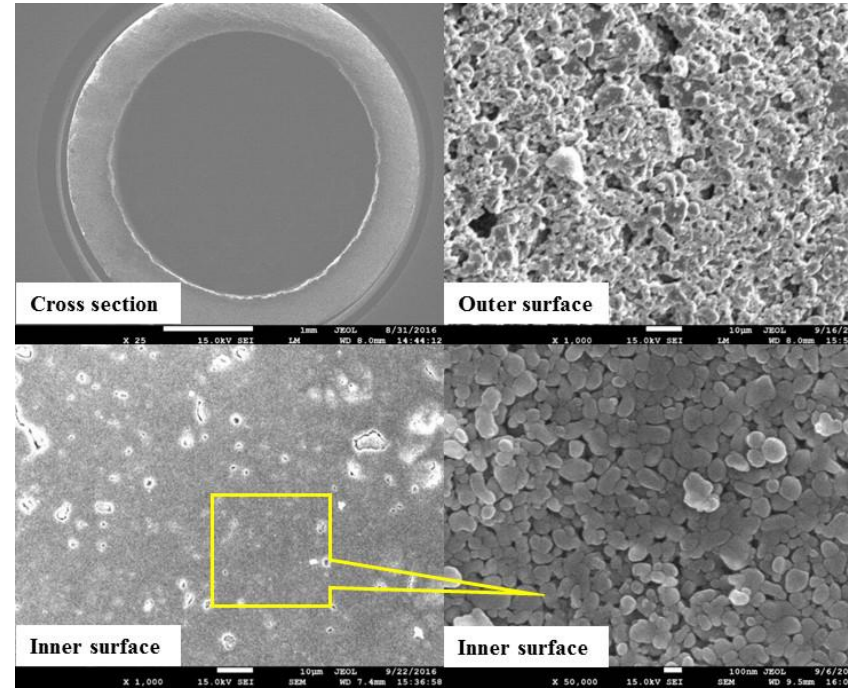

Figure 1; Morphology of pristine ceramic hollow fiber membrane.

The idea of coating PDA at the inner surface of the ceramic hollow fiber membranes is to slightly reduce the size of the surface pores and make the surface smoother, both of which are crucial to the formation of defect-free polyamide layer ${ }^{[26,27]}$. The inner surface of the ceramic hollow fiber membranes changes its color from white to brown after PDA coating as observed by bare eyes and this confirms the success in the coating.

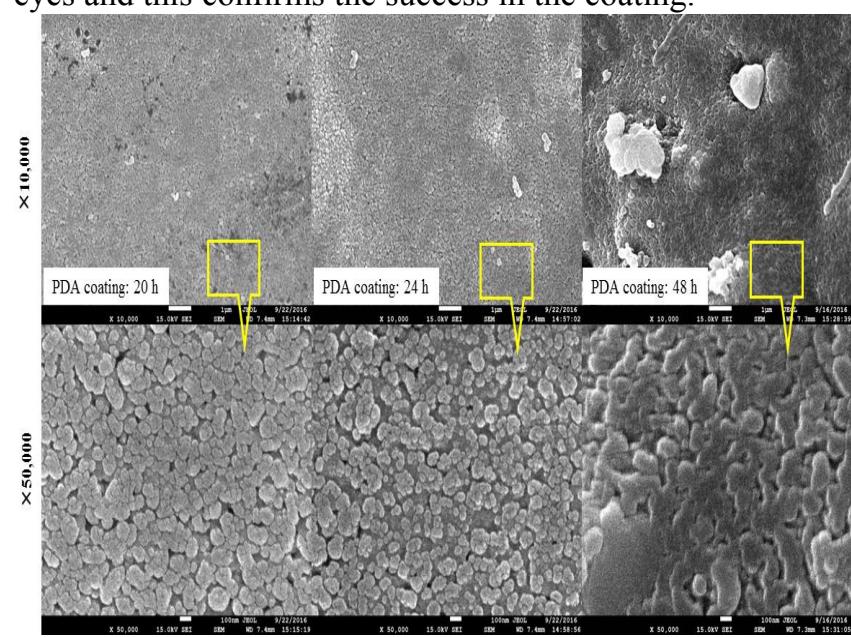

Figure 2; Morphology of PDA-coated ceramic hollow fiber membranes.

The influence of the PDA coating on the surface morphology can be seen from Figure 2. Clearly, some large pores and voids become smaller after the PDA coating. If the coating time is too short, i.e., $<20 \mathrm{~h}$, there is no obvious change in the surface morphology (images not shown). Too long PDA coating would completely alter the surface morphology, forming bumps and blocking the original surface pores. Upon $24 \mathrm{~h}$ PDA coating, the inner surface of the ceramic hollow fiber membranes is smooth with the surface pores efficiently reduced to the dimensions suitable for interfacial polymerization. Comparing the SEM image of the pristine membrane with that after $24 \mathrm{~h}$ PDA coating, PDA not only deposits on the membrane surface and form a layer but also enters the large pores or voids and reduce their dimension by depositing at the pore orifice. Presumably, PDA forms a continuous layer on top of the surface once the pores or voids are completely filled (e.g., $48 \mathrm{~h}$ PDA coating). After $24 \mathrm{~h}$ PDA coating, the clean water flux of the ceramic hollow fiber membrane drops from 193.5 to $121.9 \mathrm{LMH}$ as measured in a lab-scale filtration system at 0.5 bar transmembrane pressure. The reduction in the water flux is a direct evidence of the success in adjusting the membrane surface pores.

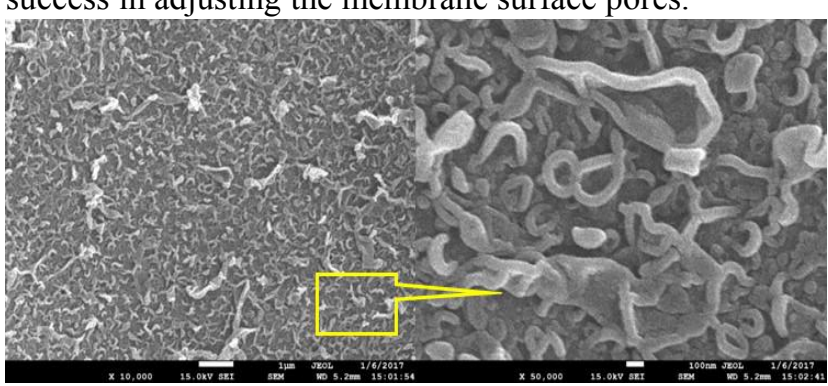

Figure 3; Morphology of ceramic TFC hollow fiber membrane.

Figure 3 presents the SEM images of the fabricated ceramic TFC hollow fiber membranes. The surface morphology is obviously different from that of the pristine and PDA-coated membranes. With a continuous polyamide layer formed on the top of the PDA-coated ceramic substrate, the surface is relatively rough and shows a typical "ridge-and-valley" morphology ${ }^{[26,27]}$. The thin polyamide film of the prepared membrane is the selective layer whose nature primarily determines the water permeation and solute rejection characteristics.

\subsection{Characteristics of draw solutions}

As the osmotic pressure difference across the membrane is the driving force in the FO process, draw solutions at increased concentrations are always expected to achieve high water flux. The most popular draw solute used in scientific research is $\mathrm{NaCl}$ because it is cheap and its aqueous solution offers acceptable osmotic pressure. The serious issue of $\mathrm{NaCl}$-based draw solutions is the reverse permeation, not only losing $\mathrm{NaCl}$ draw solutes but also contaminating the feed (for the cases of 
liquid product enrichment). Recently, FeNaCA has been synthesized in our lab and its aqueous solutions were also used as draw solutions in FO tests.

\begin{tabular}{lllll}
\hline \multirow{2}{*}{$\begin{array}{l}\text { Concentratio } \\
\text { n(M) }\end{array}$} & $\begin{array}{l}\text { Osmotic } \\
\text { (bar) }\end{array}$ & pressure & Relative viscosity \\
\cline { 2 - 5 } & NaCl & $\begin{array}{l}\text { FeNaC } \\
\text { A }\end{array}$ & NaCl & $\begin{array}{l}\text { FeNa } \\
\text { CA }\end{array}$ \\
\hline & & & & \\
0.25 & 8.9 & 23.9 & 1.02 & 1.61 \\
0.5 & 22.8 & 47.6 & 1.04 & 2.47 \\
1.0 & & & & \\
& 46.77 & 89.6 & 1.09 & 8.46 \\
& & & & \\
\hline
\end{tabular}

Table 1. Osmotic pressure and relative viscosity of $\mathrm{NaCl}$ and $\mathrm{FeNaCA}$ draw solutions

As shown in Table 1, the osmotic pressure and relative viscosity are proportional to the concentration of both draw solutions. At the same concentration, FeNaCA solution always shows much higher osmotic pressure and relative viscosity than $\mathrm{NaCl}$ solution. The relative viscosity of $\mathrm{FeNaCA}$ solutions increases abruptly when the concentration is higher than 1.0 M. Higher viscosity might influence the diffusion of draw solutes either within the boundary layer at the membrane surface (AL-DS mode) or within the porous substrate (AL-FS mode). Its direct impact is the deterioration of concentration polarization, which is considered as the main reason for low osmotic efficiency ${ }^{[28]}$. Nevertheless, the relative viscosity of FeNaCA solutions is comparable to polyacrylic acid sodium (PAA-Na) solutions at similar osmotic pressures $^{[29]}$.

\subsection{Intrinsic properties of the ceramic TFC hollow fiber membranes}

Initially, the ceramic TFC hollow fiber membranes were subjected to water permeation tests in order to determine the pure water permeability. The water flux was very low even when the transmembrane pressure was increased to 1.5 bar. This provides additional evidence that the inner surface of the PDA-coated ceramic substrate is completely covered by the polyamide layer formed through interfacial polymerization and the polyamide layer is relatively thick. This is acceptable because the membrane is developed for the enrichment of liquid products (e.g., beverage and pharmaceutical) and selectivity of the membrane is critical to keep the quality of the enriched products.

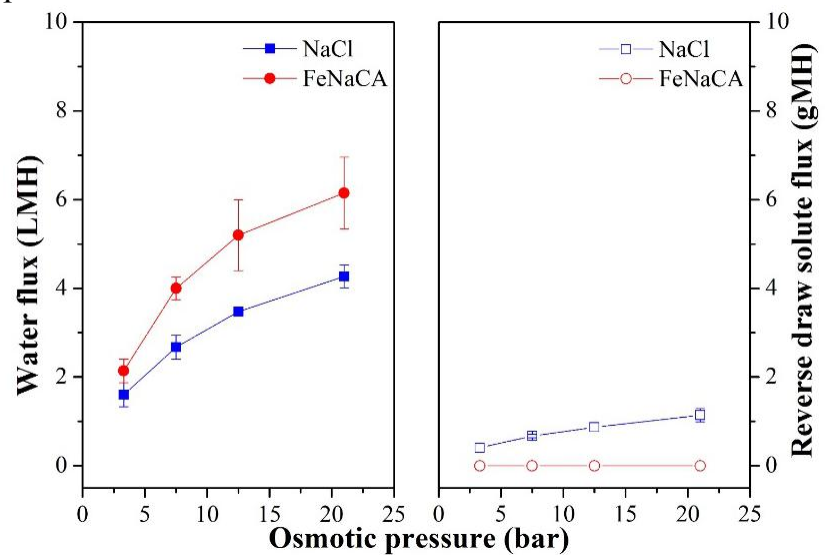

Figure 4; FO performance of the ceramic TFC hollow fiber

Membranes under DS-SL mode.

The water permeation test in filtration system was not proceeded due to very low water flux. Instead, the ceramic TFC hollow fiber membranes were tested in the FO process using $\mathrm{NaCl}$ draw solutions with osmotic pressures ranging from 2.5 to 22.5 bar at the DS-SL mode. The water fluxes and reverse draw solute fluxes generated by the ceramic TFC hollow fiber membranes are 1.60, 2.67, 3.47 and 4.27 LMH and 0.41, 0.67, 0.87 and $1.14 \mathrm{gMH}$, respectively (Figure 4). Following the methods by Tiraferri and co-workers ${ }^{[25]}$, the values of $\mathrm{A}$, B and $S$ are determined at $0.854 \mathrm{LMH} \cdot$ bar $^{-1}, 0.186 \mathrm{LMH}$ and $1720 \mu \mathrm{m}$, respectively. The $\mathrm{A}$ value below 1 $\mathrm{LMH} \cdot$ bar $^{-1}$ shows that the ceramic TFC hollow fiber membrane has a relatively dense selective layer but it is comparable to other TFC membranes ${ }^{[26,27,30]}$. The draw solute permeability $B$ has a very small value of 0.186 $\mathrm{LMH}$, indicating the excellent permselectivity of the ceramic TFC hollow fiber membranes. This is extremely important for this study which aims at liquid product enrichment. Low draw solute permeability means less draw solutes reversely permeating to the feed side, not only reducing the frequency to top up draw solutes in order to maintain the productivity but also largely mitigating the influence of draw solutes on the purity of 
the enriched product (e.g., liquid food as the feed). The relatively large $\mathrm{S}$ value of $1720 \mu \mathrm{m}$ is resulted from the wall thickness $(500 \mathrm{~m})$, of the pristine ceramic hollow fibers. Though large $\mathrm{S}$ value means more serious internal concentration polarization, the high porosity of the ceramic substrate would significantly reduce the resistance to water transport and this would definitely cancel out the negative effect of the prolonged travel distance (equivalent to fiber wall thickness) of water molecules. Moreover, the thick fiber wall make the membrane more robust and allow the thin polyamide layer to perform stably under various conditions.

\subsection{FO Performance}

As discussed in Section 3.3, FeNaCA solutions always generate higher osmotic pressure as compared with $\mathrm{NaCl}$ solutions at same concentrations. To make fair comparison, the FO tests were conducted using FeNaCA and $\mathrm{NaCl}$ solutions at same osmotic pressures instead of same concentrations. The ceramic TFC hollow fiber membranes were evaluated with running the draw solution at the lumen (i.e., DS-AL mode) or at the shell side (i.e., DS-SL mode), respectively. With DI water as the feed, the results under DS-SL mode are shown in Figure 4 while the results under DS-AL mode are shown in Figure 5.

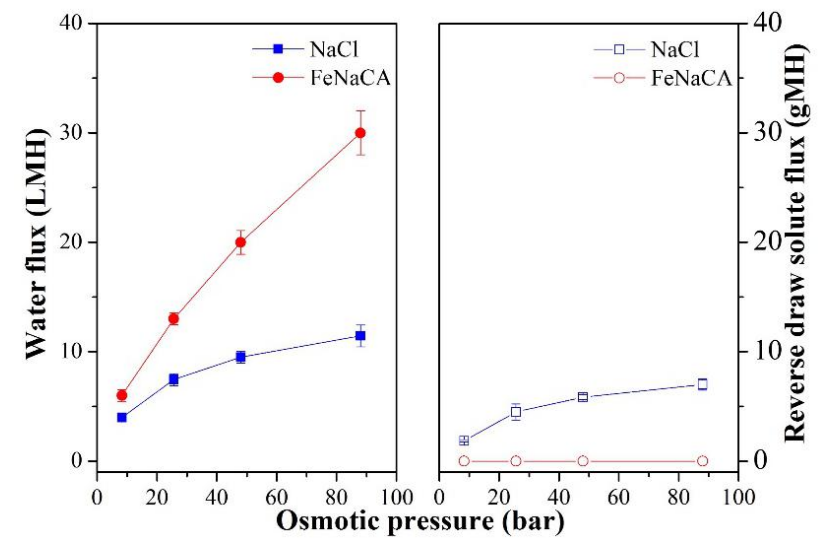

Figure 5; FO performance of the ceramic TFC hollow fiber membranes under AL-DS mode.

For both draw solutions, the water flux increases with increasing the osmotic pressure while FeNaCA draw solutions always create higher water fluxes than $\mathrm{NaCl}$ draw solutions at the same osmotic pressures. The increase in the water flux is not directly proportional to the increase of osmotic pressure due to the dilution effect, i.e., dilutive concentration polarization, which is obviously more serious at DS-SL mode and the trend is consistent with previous studies ${ }^{[31,32]}$. As well, the influence of dilutive concentration polarization on the water flux is more significant at increased draw solution concentrations. Though FeNaCA solution is more viscous than $\mathrm{NaCl}$ solution, it is interesting to note that the difference in the water fluxes created by FeNaCA and $\mathrm{NaCl}$ draw solutions becomes larger at increased osmotic pressures. Namely, the dilution effect of FeNaCA draw solutions is less significant than that of $\mathrm{NaCl}$ draw solutions. It might be resulted from the difference in intrinsic properties of draw solutes and the interaction between draw solutes and the membrane surface or substrate. The phenomenon is under investigation and the results will be reported in a separate paper in near future.

In the osmotic pressure ranges of 3.3-21 and 8.3-89.6 bar, the reverse draw solute fluxes are 0.41-1.14 and 1.85-7.0 $\mathrm{gMH}$, respectively for $\mathrm{NaCl}$ draw solutions (Figure 4 and Figure 5). However, FeNaCA draw solutes are not detectable in the feed water for all FO experiments, indicating nil or negligible reverse diffusion of FeNaCA draw solutes to the feed. Regardless of water flux or reverse draw solute flux, FeNaCA apparently outperforms $\mathrm{NaCl}$ as the draw solute. These results disclose from another perspective that the fabricated ceramic TFC hollow fiber membranes are defect free and the surface pores are exclusively at molecular level (or equivalent to the dimension of free volume).

It is known that many liquid products or aqueous solutions of the products need to be concentrated in the production process while they are opt to be denatured by inorganic salts or are sensitive to heating at elevated temperatures. One of such products is protein which is labile and heat sensitive. However, protein enrichment is an essential step in protein production ${ }^{[33]}$. With BSA as the model protein, the ceramic TFC hollow fiber membranes are evaluated for protein enrichment in the FO process with $\mathrm{NaCl}$ or FeNaCA draw solutions at 47.6 bar osmotic pressure. 


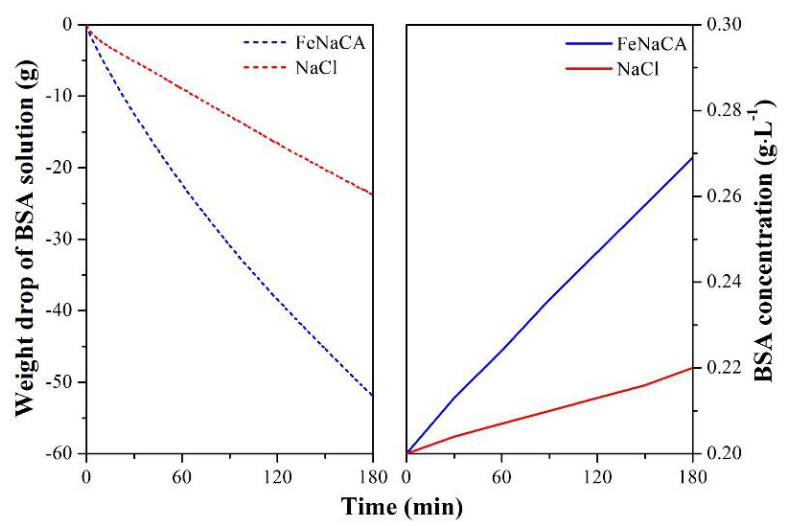

Figure 6; Weight drop of BSA solution and change in BSA concentration in the FO enrichment experiment.

As shown in Figure 6, the FeNaCA draw solution incurs a faster weight drop of the protein solution than $\mathrm{NaCl}$ draw solution. As a result, it induces a faster increase in the protein concentration. After the $180 \mathrm{~min}$ FO experiment, the BSA concentration increases by $35 \%$ and $10 \%$ by using $\mathrm{FeNaCA}$ and $\mathrm{NaCl}$ draw solutions, respectively. The weight change in both tests slightly decreases with time because the draw solution is gradually diluted with drawing more and more water from the protein solution. The average water fluxes are $12 \mathrm{LMH}$ for FeNaCA draw solution and 5.3 $\mathrm{LMH}$ for $\mathrm{NaCl}$ draw solution, respectively. Faster BSA enrichment as shown in Figure 6 proves again the better FO performance of $\mathrm{FeNaCA}$ over $\mathrm{NaCl}$ as $\mathrm{FO}$ draw solute. It should be noted both water fluxes are lower than that observed in FO experiments using DI water as the feed. The reduction in the water flux might be mainly resulted from two factors. On one hand, the osmotic driving force is gradually reduced. With drawing water from the BSA solution, the draw solution is getting diluted while the BSA solution is getting concentrated, i.e., the osmotic pressure decreasing at the draw solution side but increasing at the feed side. As a result, the effective osmotic driving force across the FO membrane drops. On the other hand, BSA protein enters the porous substrate and its aggregation is unavoidable. The protein aggregates may block the membrane pores (i.e., the flow channels of water) and increase the overall resistance for water transport.

It would be necessary to understand whether BSA protein maintains its original property after FO enrichment. CD spectrum is a valuable tool for assessing the structural relationships between native and recombinant protein as well as wild-type and mutant protein $^{[34]}$. For BSA in aqueous solution, the CD spectrum is characteristic of chromophores of peptide bond, monitored by the two well-defined ellipticity values at 208 and $222 \mathrm{~nm}$, respectively, due to $\pi \rightarrow \pi^{*}$ and $\mathrm{n} \rightarrow \pi^{*}$ transition in the peptide bonds of $\alpha$-helix ${ }^{[33]}$. To investigate the possible influence of reversely leaked $\mathrm{FeNaCA}$ or $\mathrm{NaCl}$ solutes on BSA, BSA solutions before and after FO enrichment were subjected to $\mathrm{CD}$ measurement and the $\mathrm{CD}$ spectra are presented in Figure 7.

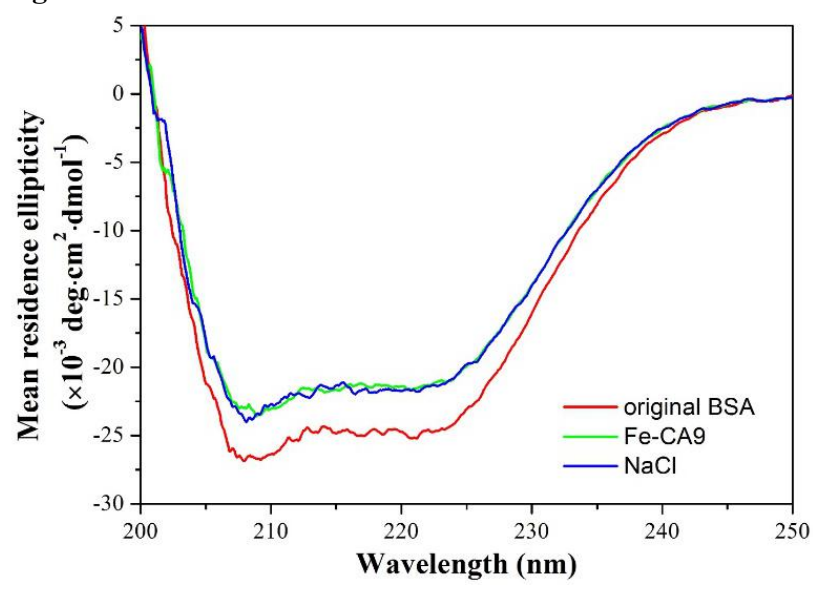

Figure 7; CD spectra of original and FO-enriched BSA.

After FO enrichment, CD spectra show the reduction in negative ellipticity without significant shift of the peaks. This means that the decrease of $\alpha$-helix content might be resulted from the aggregation induced by conformational changes of BSA [35]. It is noticed that the broad peak centered at $208 \mathrm{~nm}$ becomes a little narrower and sharper after FO enrichment using $\mathrm{NaCl}$ draw solution. This change indicates that the structure of $\mathrm{BSA}$ is denatured by $\mathrm{NaCl}$ leaked from the draw solution. There would be mutant in the BSA solution at higher $\mathrm{NaCl}$ concentrations. Whilst, BSA enriched by FeNaCA draw solution shows a peak at 208 $\mathrm{nm}$ that is almost identical to that of the original BSA. This is another experimental observation proving that $\mathrm{FeNaCA}$ is a desired draw solute.

\section{Conclusion}

Robust and defect-free ceramic TFC hollow fiber membranes have been developed and studied for FO applications. Formation of the gutter layer is important to make the ceramic membrane surface suitable for 
interfacial polymerization. The ceramic TFC FO hollow fiber membranes exhibit acceptable water permeability (0.854 LMH/Bar) and highly porous substrate $(1720 \mathrm{~m}$ for $\mathrm{S}$ parameter). In the osmotic pressure ranges of 3.3-21 and 8.3-89.6 bar, water fluxes of 2.1-6.1 and 6.0-30.0 LMH are obtained at DS-FS and DS-AL modes, respectively, without detectable reverse draw solution leakage using proprietary FeNaCA draw solutions. The ceramic TFC FO hollow fiber membranes and the FeNaCA draw solution (47.6 bar osmotic pressure) are explored for BSA protein enrichment. At DS-AL mode, an average water flux of $12 \mathrm{LMH}$ is obtained in a $3-\mathrm{h} \mathrm{FO}$ test and the concentration of BSA is increased by $35 \%$. CD measurement shows that BSA is not denatured and it maintains its property after the FO enrichment experiment. All the experimental results indicate that the developed ceramic TFC hollow fiber membranes are defect-free and are applicable for liquid product enrichment via FO processes.

\section{Acknowledgements}

The authors would like to thank the Singapore Ministry of Education for funding this research with grant number MOE2014-TIF-1-G-041. Thanks are also due to Center of Innovation Environmental and Water Technology, Ngee Ann Polytechnic for the equipment for materials characterization.

\section{References}

1. L.A. Hoover, W.A. Phillip, A. Tiraferri, N.Y. Yip, M. Elimelech, forward with osmosis: emerging applications for greater sustainability, Environ. Sci. Technol. 45 (2011) 9824-9830.

2. R. McGinnis, M. Elimelech, global challenges in energy and water supply: the promise of engineered osmosis, Environ. Sci. Technol. 42 (2008) 8625-8629.

3. A. Achilli, T. Cath, E. Marchand, A. Childress, The forward osmosis membrane bioreactor: a low fouling alternative to MBR processes, Desalination 239 (2009) 10-21.

4. C. Klaysom, T.Y. Cath, T. Depuydt, I.F.J. Vankelecom, Forward and pressure retarded osmosis: potential solutions for global challenges in energy and water supply, Chem. Soc. Rev. 42 (2013) 6959-5989.

5. J.T. Arena, S.S. Manickam, K.K. Reimund, P. Brodskiy, J.R. McCutcheon, Characterization and performance relationships for a commercial thin film composite membrane in forward osmosis desalination and pressure retarded osmosis, Ind. Eng. Chem. Res. 54 (2015) 11393-11403.
6. Y. Cui, Q. Ge, X.Y. Liu, T.S. Chung, Novel forward osmosis process to effectively remove heavy metal ions, J. Membr. Sci. 467 (2014) 188-194.

7. J.R. McCutcheon, R.L. McGinnis, M. Elimelech, A novel ammonia-carbon dioxide forward (direct) osmosis desalination process, Desalination 174 (2005) 1-11.

8. Q. Yang, K.Y. Wang, T.S. Chung, A novel dual-layer forward osmosis membrane for protein enrichment and concentration, Sep. Purif. Technol. 69 (2009) 269-274.

9. Q. Ge, T.S. Chung, Oxalic acid complexes: promising draw solutes for forward osmosis (FO) in protein enrichment, Chem. Commun. 51 (2015) 4854-4857.

10. E.M. Garcia-Castello, J.R. McCutcheon, M. Elimelech, Performance evaluation of sucrose concentration using forward osmosis, J. Membr. Sci. 338 (2009) 61-66.

11. Q. Ge, M. Ling, T.S. Chung, Draw solutions for forward osmosis processes: Developments, challenges, and prospects for the future, J. Membr. Sci. 442 (2013) 225-237.

12. S. Karan, Z. Jiang, A.G. Livingston, Sub-10 nm polyamide nanofilms with ultrafast solvent transport for molecular separation, Science 348 (2015) 1347-1351.

13. J. Su, Q. Yang, J.F. Teo, T.-S. Chung, Cellulose acetate nanofiltration hollow fiber membranes for forward osmosis processes, J. Membr. Sci. 355 (2010) 36-64.

14. S. Zhang, K.Y. Wang, T.-S. Chung, H. Chen, Y.C. Jean, G. Amy, Well-constructed cellulose acetate membranes for forward osmosis: minimized internal concentration polarization with an ultra-thin selective layer, J. Membr. Sci. 360 (2010) 522-535.

15. R. Wang, L. Shi, C.Y. Tang, S. Chou, C. Qiu, A.G. Fane, Characterization of novel forward osmosis hollow fiber membranes, J. Membr. Sci. 355 (2010) 158-167.

16. N.Y. Yip, A. Tiraferri, W.A. Phillip, J.D. Schiffman, M. Elimelech, High performance thin film composite forward osmosis membrane, Envir. Sci. Technol. 44 92010) 3812-3818.

17. R.C. Ong, T.S. Chung, Fabrication and positron annihilation spectroscopy (PAS) characterization of cellulose triacetate membranes for forward osmosis, J. Membr. Sci. 394-395 (2012) 230-240.

18. G. Han, S. Zhang, X. Li, N. Widjojo, T.-S. Chung, Thin film composite forward osmosis membranes based on polydopamine modified polysulfone substrates with enhancements in both water flux and slat rejection, Chem. Eng. Sci. 80 (2012) 219-231.

19. X. Li, S. Zhang, F.J. Fu, T.-S. Chung, Deformation and reinforcement of thin-film composite (TFC) polyamide-imide (PAI) membranes for osmotic power generation, J. Membr. Sci. 434 (2013) 204-217. 
20. J.K. Holt, H.G. Park, Y. Wang, M. Stadermann, A.B. Artyukhin, C.P. Grigoropoulos, A. Noy, O. Bakajin, Fast mass transport through sub-2-nanometer carbon nanotubes, Science 312 (2006) 1034-1037.

21. M. Elimelech, W.A. Phillip, the future of seawater desalination: energy, technology, and the environment, Science 333 (2011) 712-717.

22. G. Han, Z.L. Cheng, T.-S. Chung, Thin-film composite (TFC) hollow fiber membrane with double-polyamide active layers for internal concentration polarization and fouling mitigation in osmotic processes, J. Membr. Sci. 523 (2017) 497-504.

23. T.Y. Cath, A.E. Childress, M. Elimelech, Forward osmosis: Principles, applications, and recent developments, J. Membr. Sci. 281 (2006) 70-87.

24. Q. Ge, F. Fu, T.-S. Chung, Ferric and cobaltous hydroacid complexes for forward osmosis (FO) processes, Water Res. 58 (2014) 230-238.

25. A. Tiraferri, Yip, A.P. Straub, S.R.V. Castrillon, M. Elimelech, A method for the simultaneous determination of transport and structural parameters of forward osmosis membranes, J. Membr. Sci. 444 (2013) 523-538.

26. S. Zhang, P. Wang, X. Fu, T.S. Chung, Sustainable water recovery from oily wastewater via forward osmosis-membrane distillation (FO-MD), Water Res. 52 (2014) 112-121.

27. G. Han, S.S. Chan, T.-S. Chung, Forward osmosis (FO) for water reclamation from emulsified oil/water solutions: effects of membrane and emulsion characteristics, ACS Sustainable Chem. Eng. 4 (2016) 5021-5032.

28. J. Su, T.-S. Chung, B.J. Helmer, J.S. de Wit, Understanding of low osmotic efficiency in forward osmosis: Experiments and modeling, Desalination 313 (2013) 156-165.

29. Q. Ge, J. Su, G.L. Amy, T.-S. Chung, Exploration of polyelectrolytes as draw solutes in forward osmosis processes, Water Res. 46 (2012) 1318-1326.

30. M. Yasukawa, S. Mishima, M. Shibuya, D. Saeki, T. Takahashi, T. Miyoshi, H. Matsuyama, Preparation of a forward osmosis membrane using a highly porous polyketone microfiltration membrane as a novel support, J. Membr. Sci. 487 (2015) 51-59.

31. J. Su, T.-S. Chung, Sublayer structure and reflection coefficient and their effects on concentration and membrane performance in FO processes, J. Membr. Sci. 376 (2011) 214-224.

32. J. Su, T.-S. Chung, B.J. Helmer, J.S. de Wit, Enhanced double-skinned FO membranes with inner dense layer for wastewater treatment and macromolecule recycle using Sucrose as draw solute, J. Membr. Sci. 396 (2012) 92-100.

33. C.J. Barrow, A. Yasuda, P.T. Kenny, M.G. Zagorski, Solution conformations and aggregational properties of synthetic amyloid beta-peptides of Alzheimer's disease. Analysis of circular dichroism spectra, J. Mol. Biol. 225 (1992) 1075-1093.

34. S.M. Kelly, R.J. Jess, N.C. Price, How to study protein by circular dichroism, $\gg$ Biochim. Biophys. Acta 1751 (2005) 119-139.

35. C.M. Johnson, A.R. Fersht, Protein stability as a function of denaturant concentration: the thermal stability of barnase in the presence of urea, Biochem. 34 (1995) 6795-6804. 